\title{
Producing to market specifications - the challenge for the future
}

\author{
JON MANHIRE \\ Agriculture New Zealand, PO Box 8640, Riccarton, Christchurch
}

\begin{abstract}
High-value consumer markets are demanding a continuously higher quality of products and enhanced food safety. In association with this, the increasingly competitive global market place and developments in information technology have catalysed the establishment of closer relationships and co-operation between participants in high-value supply chains. These closer relationships enhance the flow of information between participants and their ability to introduce strategies to improve efficiencies in supply as well as to decrease risks to consumers and others in the supply chain. These trends have significant implications to New Zealand farmers who will need to adopt systems to more effectively monitor and record their use of inputs and subsequent farm and stock management and make this information available to those further down the value chain. An inability to respond to these trends may result in farmers as well as processors, limited to servicing only relatively lower value markets.
\end{abstract}

Keywords: agricultural sector, information technology, New Zealand, supply chain integration, supply chain management

\section{Introduction}

For over 30 years, the real rates of return for commodities produced by the New Zealand pastoral sector have been in decline (Brown 1996). To maintain profitability, farmers have responded in a number of ways, including:

- The introduction of new management systems and technologies to increase the efficiency of production, e.g., superior animal genetics and improved pasture species

- Increases in the size of their operations

- Diversifying and intensifying their land use.

Continued reliance on traditional low-value commodity markets will continue the need for these types of response.
Alternatives to production for commodity markets are available and provide an escape from the continued erosion of product value. A feature of many of these niche markets is the satisfaction of very specific consumer demand factors that may extend outside intrinsic product quality features.

Figure 1 Consumer Demand Factors.

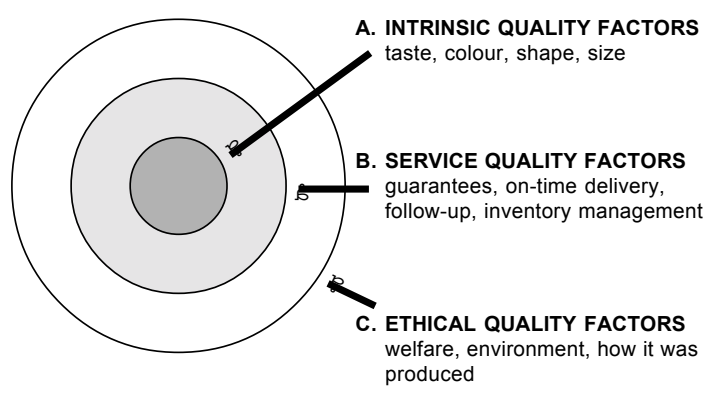

Production, processing, transportation and marketing systems have evolved to efficiently service these consumer demands. This overall strategy has been termed "supply chain management" or "supply chain integration", which is defined as;

An integrated approach that aims to satisfy the expectations of consumers through continued improvement of processes and relationships that support the efficient development and flow of products and services from producer to consumer.

This paper reviews some of the factors catalysing the growth in this approach. It identifies some of the implications to the New Zealand pastoral sector and provides some possible strategies to enable more farmers to enter these types of supply relationships.

\section{Supply chains - catalysts to their development}

The focus on the whole supply chain rather than on an individual company's performance in relationship to establishing comparative competitive advantages is a relatively recent development in western businesses. It owes much to traditional Asian business strategies of 
inter-company co-operation and the establishment of close working relationships. Factors contributing to the recent growth in interest in this approach include the following:

\section{Consumer demand}

Higher value markets require very specific products with high levels of service support. They are dynamic and require responsive servicing to be maintained.

\section{Globalisation}

The results of the 1990 GATT trade round and WTO developments have progressively removed some barriers to trade in agricultural products. This removal has been accelerated in New Zealand under the trade liberalisation policies followed since 1984. The global sourcing of food product has been driven by the growth of large supermarket and food service businesses wishing to optimise the supply of products.

\section{Reduction in risk and cost}

With increased international competition, there is continued pressure on company profitability. Strategies to minimise potential risks to satisfying consumer demand and to squeeze out cost are being adopted. These include:

Quality - Complex consumer tastes need to be satisfied. There is an increasing demand for greater information on how the product is produced and handled. The arrival of genetically modified food will increase this demand.

Volume - The requirement to ensure that targeted volumes are supplied and that loss is minimised.

Food safety - The threat to a company's brand equity, potential legal costs and the ability to maintain access to a market after a food safety scare have been major catalysts to establishing greater co-operation along food chains. Global sourcing and the often longer distances for fresh products to travel to market have also possibly increased the risks. Recent BSE, Salmonella and Dioxin food scares reinforce this point.

Cost - strategies to reduce product costs by capturing efficiencies in production, processing and handling are facilitated through a greater transparency in an integrated supply chain.

\section{Advancements in information technology}

The development of computer-based databases and the ability for their linkage via the Internet have accelerated the development of linkages between companies and the movement and use of information.

\section{Implications for the New Zealand pastoral sector}

These developments have increased the level of competition as well as created new types of barriers to market entry for the New Zealand pastoral sector. They also provide great opportunities if appropriate responses can be developed.

To succeed when exposed to international competitors, New Zealand value chains need to:

- Optimise product value by meeting attainable targeted specifications. This may require the incorporation of non-product, ethical and service quality components, e.g., Tesco's "Nature's Choice" standard, organic certification.

- Increase the efficiency of production and reduce the level of waste, e.g., supermarkets typically throw out $10 \%$ of vegetables in their stores - any reduction in this level can lead to significant gains in overall profit.

- Decrease the production and supply risks, i.e., the risks of failure to supply or to meet desired quality specifications.

- Ensure each of the components of the value chain are sustainable, e.g.,

- They are not exploiting an environmental or other subsidy.

- That no party has a highly parasitic relationship with another.

Effective supply chains require a great level of cooperation, trust and the establishment of alliances between supply chain participants. Farmers and other participants in a supply chain must ensure that their supply chain is competitive and efficient at servicing the market requirements. Some factors to consider in reviewing a supply chain include:

- The overall strategy of the participating companies in relation to:

- Their level of innovation, e.g., new products. Investment into research and development.

- Their style, e.g., power - predatory versus cooperative.

- The presence of significant market or technological insulations, e.g., well known brands, exclusive patents for production or processing technology.

- The volume, type and quality of information that they will make available.

- The business returns and the respective company's value. 
- Scale and market position, i.e., market dominance. Some of the most profitable supply chains, however, can be for very small niche markets that could be serviced by one supplier who manages the whole supply chain to the consumer. With the growth in the Internet, this model may grow.

\section{Strategies to enable the pastoral sector to respond}

The development of strategies to enhance the capability of the New Zealand pastoral sector to respond to current and future market realities should consider the following:

\section{Technology development and adoption}

New Zealand farmers have maintained their international productive competitive advantage by the adoption of a wide range of technologies which have increased farm output, quality of production and production efficiency. To enable them to actively participate in a supply chain and obtain its benefits, a range of new technologies will need to be adopted:

\section{Information technologies}

- Data collection - There will be a trend towards remote and automatic data collection systems of key production information, e.g., climate, stock movements and management.

- Data analysis and benchmarking - The transfer, aggregation and analysis of farm information will become seamless with central databases automatically harvesting relevant information from a farmer's own computer. The information will be used to satisfy market trace-back demands as well as link the production management with the final product quality. Farmers will in return receive a report benchmarking their performance against other suppliers. This information may be interpreted through various decision support tools that will provide recommendations on better management strategies.

\section{Production technologies}

- Environmentally friendly production systems Consumer demands for environmentally friendly production and safe food will strengthen the demand for production systems that rely on fewer chemicals. Technologies such as integrated pest management and organic management systems will provide some alternatives.

- Biotechnology - The potential for biotechnology to contribute to improvements in production to specification and the production of even totally new products will need to be balanced against consumer sensitivities.

\section{Industry development}

Industry level

The risks and opportunities resulting from the market and supply trends need to be identified and communicated to industry stakeholders. The development of industry level responses may create some efficiency, e.g., establishing standardisation of data collection and transfer systems.

\section{Farm-processing, marketing company level}

There is a need to continue to improve the level of understanding, trust and co-operation between the various players. The development of a shared "ownership" of market demands and the development of win-win strategies to satisfy these would be useful.

\section{Farm level}

Continued improvement in farm and business management - especially the capture and analysis of information to identify best management practices through benchmarking, will be valuable.

\section{Challenges for farmers}

The increased importance of supply chains provides a significant opportunity for New Zealand farmers who have the ability to access high-value supply chains. The challenge is to ensure that access. Attributes that will make pastoral farmers attractive include:

- The consistency and reliability of their supply.

- The quality of product - intrinsic, service and ethical product quality factors.

- Scale - the larger the supply volume, the lower the relative transaction cost to manage supply.

- Ability to innovate - development of management systems and adoption of technologies that enable the production or servicing of market needs.

- Responsiveness - ability to rapidly supply market demands.

- A good level of profitability to enable the above to happen.

\section{REFERENCE}

Brown, C. 1996. Financial viability - a long-term view. Proceedings of the New Zealand Grassland Association 58: 7-12. 
